\title{
Analysis on the Online Propaganda Business Transformation of Chinese Traditional Media During the COVID-19 Epidemic
}

\author{
Fangzheng Shi
}

\author{
St.Judes Academy, 2150 Torquay Mews, Mississauga, On, L5N 2M6 \\ *Corresponding author. Email: $3128132301 @$ qq.com
}

\begin{abstract}
Though some traditional media firms and organizations have an awareness of the necessity of transformation to new media or turn to convergence media, more accurately, few have done it thoroughly. The barriers can be various. COVID-19 virus, as a precipitately global disaster on finance and safety, has made this goal necessary to be done. This article helps those not transferred traditional media firms to possess an available guideline of promoting the online propaganda projects through the case analysis of three mainly successful transferred media companies that searched here already, CCTV, People's Daily and FENG. The reason for choosing these three organizations is quite simple; they have similar network platforms on propaganda coronavirus, which unite all forms of media such as TV and broadcast with their special column and other short video platforms. It is called media convergence utilization. Further, it is easier to move audiences when a series of recording stories of people who insisted on the front lines broadcasted off. It is called storytelling. Based on the two methods above, other traditional media companies can transform well.
\end{abstract}

Keywords: Transformation, traditional, media, propaganda, virus, convergence media

\section{INTRODUCTION}

Traditional media is one of the most impacted industries under the COVID-19 virus, which has caused the global financial crisis. To the opposite, short video applications show a booming growth trend. The epidemic has become the 'black swan' of China's economy in 2020, which will have an impact on many industries, but the data of the short videos industry has shown a growth trend. According to the data of Analysis Qianfan, in the five days from January 26th to 30, Kuaishou and Tik Tok, the average daily usage time of music users have increased nearly 100 million hours compared to before the holiday (January 1st to 23rd). According to data from Qimai, both Kuaishou and TikTok experienced a peak in downloads during the spring festival this year. In the past month, Kuaishou and TikTok's downloads exceeding 470,000 and 28, respectively.[3]

To take the responsibility of propaganda and deal with the severe financial crisis, many traditional media firms have made an effort to transfer their offline business to online forms. CCTV, People's Daily and FENG, which are analyzed below, have already set good examples for others, demonstrating professional media practitioners' determination against crisis and responsibilities to well-propaganda.

\section{PROBLEM DETAILS}

In the difficult situation of the epidemic, the Chinese government had resolutely published an unresistant policy that everyone should be forced to stay at home to quarantine except the hospital staff and aiming people. Thus this policy has stopped most of the industries running. In addition to television and the Internet, newspapers, magazines, and radio have long been forced to lose their propaganda responsibilities under such an urgent situation. Even TV audiences concentrated in the middle-aged and the elderly. Young people prefer to use mobile phones and computers to browse online news. According to the Fudan University study, IPTV users surveyed presenting that the average watching period is 1.43 days a week, down significantly from the 2010 survey.[5] Because of dominating long in this industry, traditional media firms do not want to lose new audiences and reduce incomes, starting with the online projects they are not good at. The epidemic is undoubtedly an opportunity for these traditional media to see the importance and necessity of transform. How to transform and what to do after the transformation has become the most critical issue.

\section{METHODOLOGY}

There are several mainstream media company transformation cases. While TV viewing rates have fallen, traditional media have received far fewer blows than 
television, so many media companies are ready to transform. The 2013 China Newspaper Mobile Communications Index Report, published by the people's net research institute, collected samples of 150 influential newspapers and 132 magazines in china; 149 of 150 newspapers opened Sina certified microblogs; 137 of which opened Tencent certified microblogs; 121 of which have WeChat certified public accounts, 110 of which have an apple version APP, and 105 of which have an android APP, magazines are similar to this situation.[10] Though this data shows a significant tend of transform, the real problem is they were still losing their audiences because of the intense competition with newly generated companies, which are specialists in new media and network platforms. This comprehensive epidemic has played a driving role in this process. Some enterprises and institutions take the lead in setting an example, adding new media propaganda modules to become joint media publicity. They all played a mainstay in the epidemic campaign.

\subsection{CCTV News and CCTV Video}

CCTV is China's most influential, authoritative and professional television media, as well as China's national media, playing an irreplaceable role in the propaganda of epidemic. Immediately after the central government order, it finished the task of tracking the number of infected people in real-time launched[7]. Since the outbreak of COVID-19, CCTV has continued to work on the virus's newest dynamics throughout the whole nation. Almost 100 news programs and special columns were produced during the period. In order to promote the influence of the propaganda, CCTV utilized a combination of new and traditional media forms. On January 20th, "News 1+1", one of the main TV programs of preventing the virus, broadcasted news about the coronavirus, the earliest information of the virus and substantiated it could be infected between humans, from then people started to pay attention to it.[7] Not only just "News $1+1$ " but also a series of other congener programs such as "Fighting Virus Together" were on broadcasting the latest situations as well as feasible ways to prevent and predict the appearance of viruses within a live stream connected to experts in their studios. Nanshan Zhong, Lanjuan Lee and other relatable medical researchers working on the front line have been frequenters of CCTV's every column of preventing the virus. Some of them tried to speak humorously to propagate methods of preventing and predicting while the situation being serious. Edited as short videos and then spread into all mainstream network platforms such as Weibo, WeChat and TikTok, those experts' speeches made them "internet famous." That is the new media functions. New media platforms such as "TouTiao Video" and official Weibo accounts and that of WeChat have helped the timely dissemination of epidemic information. So to news anchors, through short videos or live broadcasts, the timely spread of epidemic information with diversified information, act as "internet famous," recording vlog and short videos to interact well with the audience through those platforms.

\subsection{People's Daily and Central Kitchen}

This is a media platform," in the organizational structure, People's Daily Central Kitchen thoroughly open and integrate the "newspaper, network, end, micro" of the interview, editing and technical force to achieve integration planning, integration collection, integration processing, integration dissemination ." Chen Yulin said.[11] People's Daily Central Kitchen is a complete and integrated system. Its aim is not to make news become a product of assembly line, but to give full play to the characteristics of news specialty of different media, realize individualized news production, and meet the individualized demand of news products ." In the epidemic, the Central Kitchen is a combination of China Railway and other transport agencies of 18 media studios to launch a "see, listen, feel" [6]as the publicity content's characteristics. As can be seen, the media record effective epidemic prevention measures and precautions in the form of short video; the media spread in the form of music and poetry recitation to resonate and record the storytelling, of small people feel the heart of the first line of protest posts.[6] Working together with the railway and hospital propaganda media to cover traffic conditions, people who can not go home during the epidemic can ensure their safety on the road and feel strong friendships from so many forms of media. No longer afraid of the hardships that may be encountered on the road.

\subsection{Feng Media and Feng New Media Network Television}

Feng Satellite TV Media is one of the most prominent representatives of the transformation of newspaper and television broadcasting media in China. As early as 2005, it began the project operation of new media-founded Feng New Media, a media platform with video articles and news reports. It covers more than 20 fields of news reports and has set up a column for Phoenix TV programs, making it a large media organization. Feng Satellite TV has still maintained its multi-field and multi-report style. Not only did they launch a series of programs to promote the anti-epidemic in response to the call of the central government and the people of the whole nation, but they also invited experts in other fields for professional analysis. The impact of various areas and regions under the epidemic and possible future developments. "Secret and Great" was produced as a recoding of ordinary people who stayed on the front line to fight the virus and broadcast both in the Feng Website and the TV program. "Navigator" was produced to record the efforts those entrepreneurs and organizations have done to better people's lives and fight against it. For example, BGI Group, as one of the recorded firms, is specialized in the medical business, and they have done some crucial researches and inventions of preventing COVID-19.

And the same thing either happened to other big companies. Moreover, they invited experts to give a speech about a particular field's future progress under such a severe virus 
situation. Such as Professor Yugui Zhang, who is Dean of Shanghai International Finance and Trade College, was invited to talk about, in particular, the impact on the three major economic areas of the Yangtze River Delta, the Pearl River Delta, and the Beijing-Tianjin-Hebei region, which are the core area of China's economy, is a focus of the market and society. Feng website here helped move people through written forms. It further functions professionally on images and collections of both domestic news and abroad news, which brought the total pleasure of reading.

\section{TRANSFORMATION STRATEGIES}

\subsection{Build Their Own Media Joint Reporting Mechanism}

The 21st century is a significant era of network development. In the first ten years and twenty years of the beginning of the century, many countries have achieved rapid economic growth through the network. Many traditional businesses have also used the system to realize the transformation from entity to virtual. The epidemic has become the reason for the shift of traditional media, and with the leadership of several large enterprises, let the press people see the powerful influence after the change.

From the above three analysis cases, we can see the importance of media integration. Especially during the epidemic, when radio stations and newspapers almost stopped running the company, social networking platforms became the favourite access to information for young people and even middle-aged and older people. According to the shown data, middle-aged and older people have become the primary growth of short videos during the epidemic because of their children's recommendations.[5] Since the increasing network platform, the propaganda plate became one of the essential links. The transformation of traditional media into new media has some advantages over new media enterprises, which lies in its professionalism and authority. The basis of traditional media writing is that they have a real interview and experience of events. The editor of new media summarizes different articles and extracts a report of their own and attracts readers with novel titles. The latter writing style and style can be quickly learned and mastered, based on comparing traditional media writing skills and news accuracy and new speed.

Moreover, traditional media companies are more authoritative and correct in readers' minds than ordinary new media companies and will influence the audience.[2] As if CCTV, domestic is a household name of the authoritative television media, and when it launched the short video and professional articles on the network platform, it not only guaranteed the strength of communication but also guaranteed the depth of communication. Very good in the epidemic period to achieve broad public publicity.

\subsection{Utilize Storytelling As the Method to Record}

Network platforms are becoming popular because of their "fragmented" reading and storytelling-featured contents.[8] Compared with the heyday of traditional media, people are no longer used to reading a large section of a professional and single style of reporting analysis as directly saying manner, thus only the addition of stories will make readers motivated to read. Those stories can better be events behind the report.[9] Dr. Nanshan Zhong, who is the hero of fighting the coronavirus, reported that he immediately went to Wuhan when he knew the virus happened there without any rest and stop. A large number of his stories were broadcasted as short videos or written articles; many people were moved. Such a news story can reflect a fact that through the form of storytelling, it expresses the depth of news events, enhances the reading, information and literary nature of news reports, and realizes the social value of news dissemination. The case analysis shows that CCTV, Feng New Media and People's Daily all added a large amount of small and trivial narration in news reports. Thus how to write a story is becoming the key point Firstly, to express more details and emotions of the facty events.

American scholar Robert Hilliard believes that a fair and complete news story should be similar to a dramatic performance, "there must be obvious contradictions in the story," "keep a sense of liveness and tension in the story at all times," and "provide readers with any possible details."[9] Plots and conflicts are attractions to audiences; most of attractive articles possess both of them. To achieve more story's value on this basis, otherwise, the news that is plain and straightforward and has no twists and turns will be unwilling for the audience to spend time reading.

Secondly, people in events is the writing basis. Each event is happened based on people, thus focus on details of characters in a story could be essential. Establishing the images and corresponding points of the characters in the story, and striving to explore the factors of human nature and human affection in the news facts and the relationship between people are the main focuses. The storytelling of news writing is mainly manifested in the concrete story characteristics it produces: vivid, tortuous, and fascinating, but news writing cannot be rendered as useful as works of art. To find the cause, process, and ending of the story in the news, the most important thing is to dig out the fun or artificially create interest in news writing, which requires specific skills.

\section{CONCLUSION}

The new coronavirus has become a disaster in 2020; in the case of the hit, the trend of traditional media to new media has become very obvious and necessary. Although there have been a number of magazines, newspapers and broadcasters have started to promote their online 
propaganda sector, but nothing is more complete and fast than this disaster when the time comes, so the recruitment of new media personnel and the development of online business has become inevitable. This article focuses on the transformation of three of China's most iconic media companies and their performance in the outbreak: CCTV, Feng and People's Daily. After analyzing their advocacy, we have concluded that two approaches can be learned and used by other traditional media organizations so that they can better complete their transformation and take on the responsibility of being good media people in an outbreak. The first is to pay attention to the combination of traditional media and network media, such as CCTV and network short video combination, which can broaden the width and depth of communication at the same time. The second is to tell the story of the temperature of the news. Viewers prefer to read articles with conflicting plots rather than a professional report, in which the personality characteristics of the characters involved are incredibly important and are the second focus of the item. Only by doing these things can we really have the intensity of publicity in order to do an excellent job under the epidemic as media professionals. At last, I want to appreciate professor Wegenstein for her excellent teaching and Ms. Micheal's assistant. This paper finished with Ms. Chaya's supervision and Ms. Sun's checking, which helped me throughout the process, and I appreciate that.

\section{ACKNOWLEDGMENT}

I would like to especially thank the teachers and friends who gave me unlimited support and help during my studies. Thanks to my instructors. They have given me careful care and patient guidance, giving me encouragement and motivation, and it is precisely under her guidance and supervision.

\section{REFERENCES}

[1] Wenhao Wu, Aisong, Wang. The stratification of TV masses and viewers.

[2] Xiaolin Lou, Liping Deng. Traditional advantages of traditional media:11-16

[3] Tencent New Media. During the epidemic period, short video apps welcome the peak of downloads, and "home" content plays in the billions: 3-7

[4] Jing Wu. Take Feng New Media as an example-Talking about the integration of domestic new media and traditional media: 13-17
[5] Sohu News. Are you still watching TV? Surprising results for more than 50,000 people: 4-9

[6] Tencent Media Research Institute. Current Status and Development Examples of Chinese Media Convergence:31-33

[7] Wen Chen. Research on the transformation and development of traditional media during the epidemic: 39-51

[8] Yong Wan. On the role of short video in promoting the transformation of traditional media:1-3

[9] Qituan Wang. "Story-telling" news writing method and strategy research:

[10] people.cn Media channel. 2013 China Newspaper Mobile Communication Index Report Released. Launch of the Top 100 Newspapers and Magazines Mobile Communication Index: 30-74

[11] Sohu New. Why does the People's Daily "Central Kitchen" burst out frequently: 13-17 